\title{
CFD efFeCtiveness of ARLA32 Crystallization Prediction in SCR SYSTEMS
}

Anderson de Almeida Souza, Leandro Seizo Glovaski and Roberto Carlos de Castro Silva.

MWM Motores Diesel

E-mails: anderson.souza@ navistar.com.br, leandro.seizo@ navistar.com.br, and roberto.decastrosilva@avl.com.

\begin{abstract}
Diesel engine technology has been driven by stringent regulation. To fulfill these demands emission control systems are constantly improving. In this context exhaust gas aftertreatment development assumes an important role.

Due to emissions standards evolution which considerably reduced the limits for hazardous gases, NOx from engine combustion chamber included, some vehicles are equipped with an aqueous solution of urea (Arla32) dosing system in order to reduce, when working with a SCR (Selective Catalyst Reduction) catalyst, NOx emissions level. SCR aftertreatment system operates by dosing Arla32 inside the exhaust pipe, getting it converted to ammonia by chemical reactions and, when in contact to the catalytic material (SCR), transforms NOx molecules to Nitrogen and water. But some factors can make that part of the dosed urea solution does not convert into ammonia. The accumulation of urea and its subcomponents inside the piping causes crystallization. Exhaust systems with high level of crystallization leads to efficiency loss of NOx conversion, ammonia emission increase and vehicle performance loss due to exhaust backpressure increasing. In order to avoid the urea crystallization in vehicles equipped with Arla32 dosing system, CFD simulations are made even before a prototype sample is available. Usually, CFD analysis is performed in some operating points, in steady state condition for a short period of time. The goal of this paper is to evaluate the results obtained in CFD simulation by comparing to results in real systems tested in dynamometer
\end{abstract}

\section{INTRODUCTION}

The most important species of pollutants emitted by combustion sources, stationary or mobile are monoxide carbon, organic compounds (unburned or partially burned hydrocarbons), sulfur oxides, particulate matter $(\mathrm{PM})$ and $\mathrm{NO}_{\mathrm{x}}$.

Those agencies are constantly forcing engine and vehicle manufacturers to look for technological solutions that can reduce the emissions levels, as can be seen in figure 1 below, new technologies have been developed to achieve the new emissions results of $\mathrm{NOx}, \mathrm{CO}, \mathrm{CO}_{2}, \mathrm{HC}$ and PM. One of these technologies developed is the SCR, which uses Arla32 as reagent for NOx reduction. 


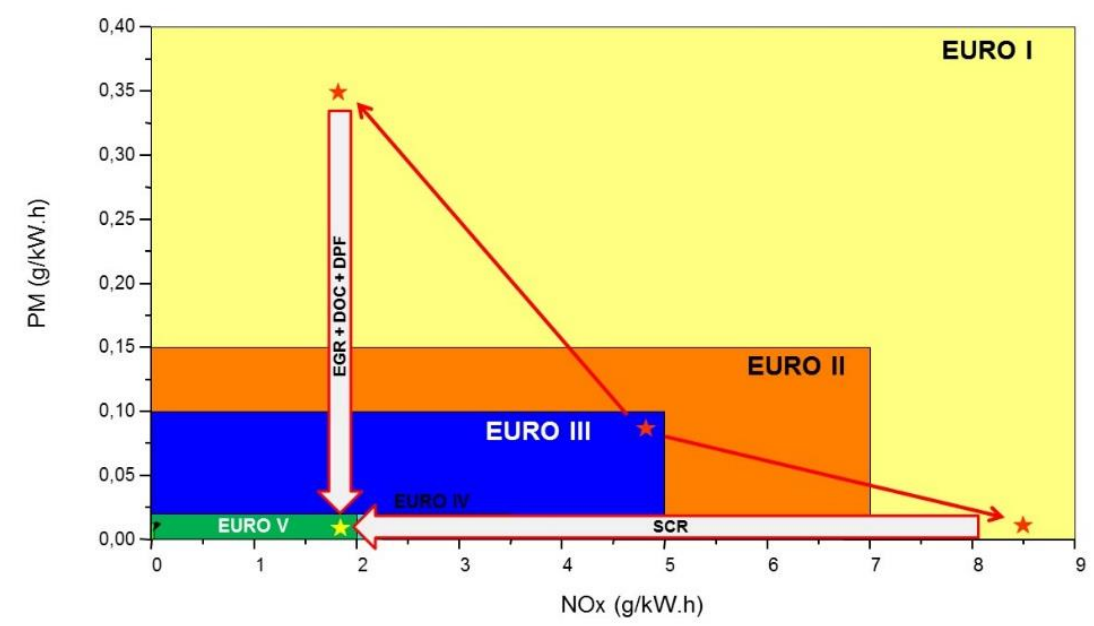

Figure 1 - Road map of Emission Standard.

In Brazil the regulatory agency is CONAMA (National Council for Environment) that regulates industrial impact on environment and it established PROCONVE standards based on EURO standards. Follow the table 1 with correlation of European and Brazilian standards.

\begin{tabular}{|c|c|}
\hline European & Brazilian \\
\hline EURO I & PROCONVE P3 \\
\hline EURO II & PROCONVE P4 \\
\hline EURO III & PROCONVE P5 \\
\hline EURO IV & PROCONVE P6 \\
\hline EURO V & PROCONVE P7 \\
\hline EURO VI & PROCONVE P8 \\
\hline
\end{tabular}

Table 1 - Correlation of European and Brazilian Diesel Emission Standard.

Nitrogen oxides or NOx is an undesired pollutant in the exhaust gases produced by the combustion process of a diesel engine due to non-ideal conditions [1]. Brazilian emission standards regulate the allowed emission level of NOx from diesel engines and this level has decreased significantly during the last decade. It is supposed to decrease even more in the near future. The on-road diesel engines produced at MWM contain a SCR system to reduce the amount of NOx in the exhaust gases. In such system, ammonia (NH3) is used as a reducing agent to convert $\mathrm{NOx}$ into nitrogen gas $\left(\mathrm{N}_{2}\right)$ and water $\left(\mathrm{H}_{2} \mathrm{O}\right)$ [2]. In a urea based SCR system a solution of urea $(32,5 \%)$ and water called Arla32 in Brazil (same as AUS32, AdBlue in Europe or DEF in USA and UK) is injected into the hot exhaust gases through atomization. The water has to evaporate before urea may decompose to $\mathrm{NH}_{3}$ [3]. Naturally, to obtain a high $\mathrm{NOx}$ conversion over the catalyst, it is of importance to achieve a high conversion of urea and a uniform mixture between $\mathrm{NOx}$ and $\mathrm{NH}_{3}$. In order to obtain this, static mixers can be installed to enhance the turbulence and break up the spray into smaller droplets.

Computational Fluid Dynamics (CFD) has been an important tool for designing and developing exhaust gas aftertreatment systems in the automotive industry. The process of evaluating the SCR performance experimentally by measuring the $\mathrm{NH}_{3}$ concentration at the inlet of the SCR catalyst is a difficult task that is both expensive and time consuming. However, numerical methods and computational technologies have been developed rapidly which enables CFD simulations to predict the atomization and chemical reactions taking place in an SCR system along the flow mixing. Hence, by predicting the flow uniformity through CFD simulations the time for the development progression has declined significantly [4]. 
This work is based on a study at MWM that analyzed the effect of decomposition pipe design, mixer position and design and position of urea injector in order to minimize the urea deposits formation on SCR system.

The aim of this work is to study the mixing phenomena of urea and exhaust gases in the mixing pipe which is located upstream of the SCR catalyst. The interaction between the spray, the turbulent flow field and the mixer elements is studied. The results are assessed as trends in order to get a better knowledge of how the system works and what modifications would improve the results in terms of urea conversion and the mixing performance. The methods for evaluating the system performance are analyzed and developed in order to get a better estimation of the NOx conversion.

\section{SELECTIVE CATALIYST REDUCTION (SCR)}

The $\mathrm{NO}_{\mathrm{x}}$ produced during the combustion process depends on numerous factors such as fuel composition, operation mode, combustion chamber design, among other factors. Each factor plays an important role on the final $\mathrm{NO}_{\mathrm{x}}$ produced. Some control techniques take advantage of the kinetic mechanism of $\mathrm{NO}_{\mathrm{x}}$ in contact with agents acting in different ways leading to reduction or complete annulment of NOx. Among these techniques is the Selective Catalytic Reduction (SCR) as mentioned.

Arla32 dosing systems, used by SCR (Selective Catalyst Reduction) equipped vehicles to accomplish EURO IV and newer emissions requirements, were developed with the goal of decrease NOx emissions from diesel cycle engines. Arla32 is an aqueous urea solution composed of $32.5 \%$ of urea and $67.5 \%$ of distilled water (weight proportion). This concentration permits the lowest freezing temperature of the solution, as shown in the Figure 1 .

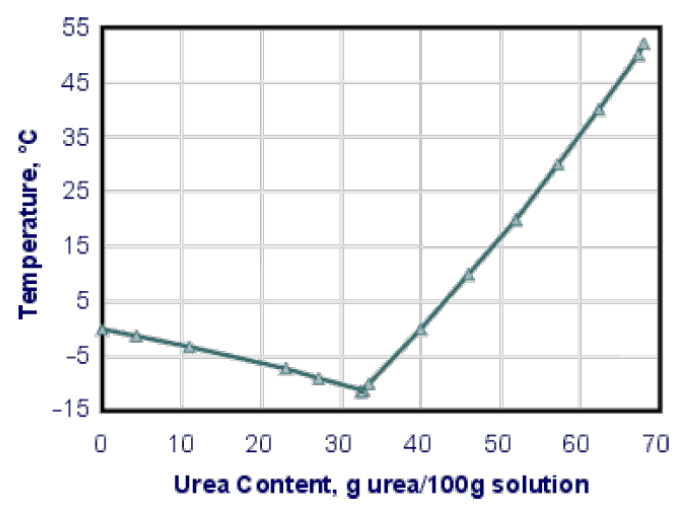

Graph 1 - Freezing point of Urea solutions.

In a SCR system, ammonia $\left(\mathrm{NH}_{3}\right)$ is used as a reducing agent to convert NOx into nitrogen gas $\left(\mathrm{N}_{2}\right)$ and water $\left(\mathrm{H}_{2} \mathrm{O}\right)$. The main advantage with this system is the high NOx conversions $(85 \%$ or higher). The disadvantages involve the space required for the catalyst, operating costs, formation of other emissions ( $\mathrm{NH}_{3}$ slip) and formation of undesirable compounds which may lead to catalyst masking and deactivation. The $\mathrm{NH}_{3}$ slip can be controlled by installing an oxidation catalyst downstream the SCR system. Although the SCR system has some drawbacks, 
the technology has been chosen by the majority of the diesel engine manufactures, due to absence of better options to meet the European standards.

The Arla32 dosing system, basically, injects the solution into exhaust pipe of the vehicle. So, the solution will be converted to ammonia via two chemical processes: thermolysis and hydrolysis.

During the thermolysis, the urea in the solution is decomposed in ammonia and isocyanic acid. During the hydrolysis, the isocyanic acid reacts with the water and is converted to ammonia and carbon dioxide. Those reactions can be seen in the figure 2 .

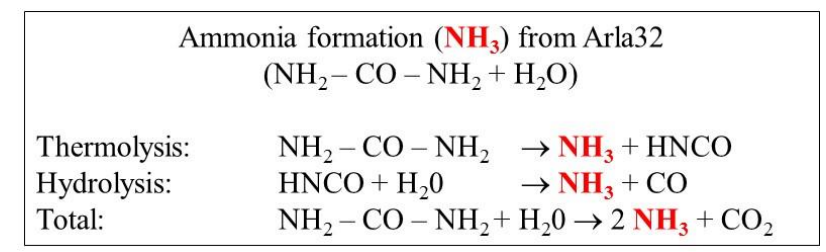

Figure 2 - Ammonia formation from Arla32 by thermolysis and hydrolysis processes.

This ammonia is the element that will react with the NOx coming out from the engine while it passes through the catalyzed substrate, according to the reactions in the figure 3.

$$
\text { SCR reaction: } \quad 4 \mathrm{NH}_{3}+2 \mathrm{NO}+2 \mathrm{NO}_{2} \rightarrow 4 \mathrm{~N}_{2}+6 \mathrm{H}_{2} \mathrm{O}
$$

Figure 3 - SCR reaction from inside of the catalyst where the ammonia and NOx are converted in Nitrogen and water.

The amount of Arla32 that is dosed in the exhaust stream is calibrated according to the engine out NOx, the exhaust gas flow and temperature, catalyst temperature and some other parameters from the vehicle.

During certain conditions, uncompleted decomposition of urea can cause formation of undesired by-products deposits which might form a solid deposit on the surfaces of the exhaust pipe. As a consequence of the incomplete decomposition of urea and formation of deposits, $\mathrm{NH}_{3}$ formation is also reduced and the catalyst surface may be affected, decreasing $\mathrm{NOx}$ reduction efficiency. The formation of solid deposits from urea by-products is mainly dependent on temperature. In studies made by Xu et. al [5] solid deposits in the SCR has been reported at temperatures below $300^{\circ} \mathrm{C}$. At temperatures above $300^{\circ} \mathrm{C}$, the majority of the deposits vaporizes. Temperature below $300^{\circ} \mathrm{C}$ is reached when the engine has a relatively low work load and the exhaust gas stream is not heated to higher temperature.

The urea solution decomposes slowly at ambient temperature, but it is rapid if the solution is heated. Urea starts to decompose at $160^{\circ} \mathrm{C}$, but it cannot reach a complete decomposition in the gas phase at temperatures and residence times of typical diesel exhaust. Part of the decomposition also occurs in the catalyst inlet.

When injecting urea into SCR systems at low temperatures, some undesired by-products may be formed, including cyanuric acid, biuret, or melamine. There is also a possibility of SCR catalyst fouling by products of incomplete urea decomposition. In the figure 4 it can be see the sub products of incomplete urea decomposition. 

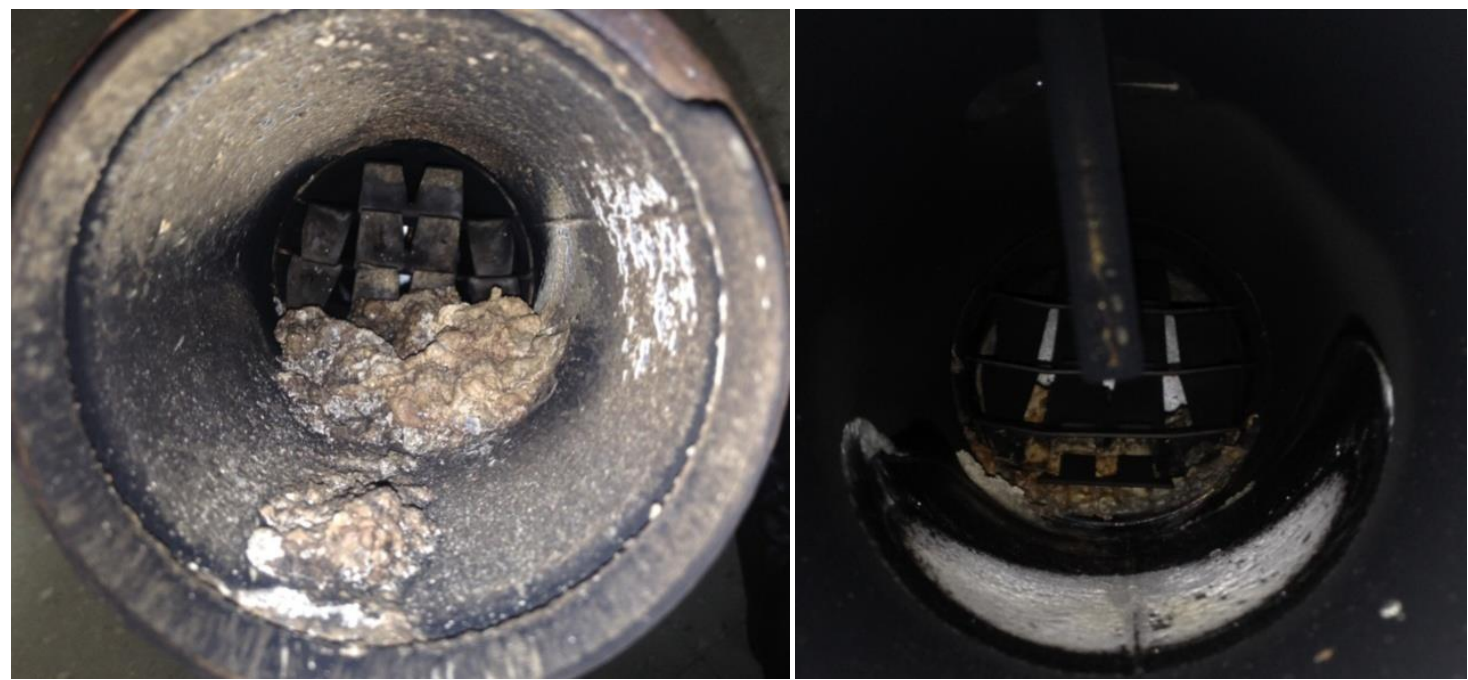

Figure 4 - Undesired crystallization in the decomposition pipe of AUS 32 by-products.

The Arla32 solution is sprayed into the exhaust gases flow upstream of the catalyst. The atomization of liquids is a common process unit operation where a bulk fluid is transformed into a spray system. The main intention of atomization processes is to maximize the gas-liquid interface since all transport processes are directly dependent upon this surface area and the exchange between the phases will improve with an increased surface. The exchange between the phases in a spray system is increased by several orders of magnitude compared to the case where the liquid is not disintegrated through atomization [6].

The interaction between the spray and the wall involves complex mechanisms since the outcome of an impinging droplet depends on several parameters including properties of the droplets, the surrounding gas and the wall. Accordingly, there are several different outcomes from an impinging droplet which may be summarized by adhesion, rebound, spread, splash, rebound with break-up and break-up [7].

The SCR system can be controlled by the engine controller unit (ECU) or by a specific dosing controller unit (DCU). The figure 5 shows one example of a complete SCR system.

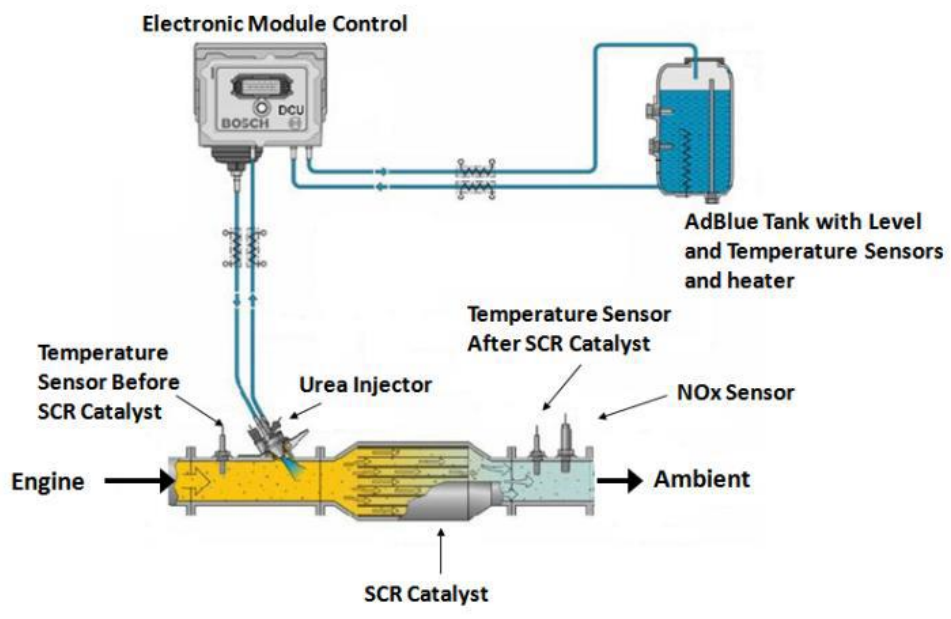

Figure 5 - SCR schematic components.

Aside the controller, the other key components of a typical SCR system are:

- Arla32 tank: for the solution storage

- Arla32 tank sensors: for diagnosis and driver inducement 
- Arla32 pump: for transferring the solution from the tank to the injector at determined pressure for atomization

- Arla32 injector or doser: for properly injection of Arla32 into exhaust stream

- Exhaust sensors: for operating conditions evaluation and diagnosis

The amount of Arla32 to be dosed in the exhaust pipe depends on the instantaneous operating conditions of the catalyst and the engine. The system is calibrated to inject the amount of urea so that the required NOx conversion performance at catalyst is achieved. But this quantity must be limited by the operating conditions of the injector spray, like exhaust flow and temperature.

\section{COMPUTATIONAL FLUID DYNAMICS (CFD)}

CFD is a powerful tool used to predict the SCR performance in a simulation environment; nowadays we have a lot of software brands that reach the various objectives of this simulation. We will not compare the efficiency of the tools in this study since that the objective of this study is evaluate the efficiency of the CFD in general in order to predict the urea crystallization. There are several information that justify the CFD simulation, spray characteristic, urea wall film, thermolysis process, exhaust backpressure, flow uniformity and centricity, risk of substrate damage and ammonia uniformity. As we can see, there are no specific outputs from the simulation related to urea crystallization, but some of these outputs can be used in order to mitigate the risk or improve the system in order to avoid the urea crystallization.

\subsection{Simulation Inputs}

The simulation usually is done for a small period of time, in steady state condition. In order to do a CFD simulation of a dosing event the following data are input for the simulation software:

- Steady state operating point conditions: exhaust gas flow, gas temperature and static pressure, Arla32 dosing ratio, Arla32 temperature and environmental temperature.

- Exhaust pipe 3D model: it must contain whole internal elements that interface the gas flow.

- Exhaust pipe parameters: heat transfer coefficient, thermal insulation characteristics.

- Substrate parameters: diameter, length, cell density, wall thickness

- Spray characteristics: sauter mean diameter, spray angle, size distribution

For this study, the software used was AVL Fire ${ }^{\mathrm{TM}}$.

\subsection{Simulation Outputs}

\subsubsection{Spray characteristics:}

The injector operating must be carefully designed in order to improve the Arla32 atomization while it flows through exhaust pipe. Homogeneous mixture is desired to ensure successful evaporation of urea in exhaust gas. A turbulent flow improves the mixing efficiency when compared to a laminar flow, so it is desired to have turbulence in the exhaust. 
Injector characteristics are provided by the system manufacturer according to empirical measurements. Its characteristics depends on injection pressure, injector holes design, number of holes, spray angle etc, affecting the droplet size and distribution. Each variant has a different performance even using the same urea dosing system. Computational simulation of the fluid dynamics results in the behavior of the spray in simulated condition. Different from the spray pattern provided by the injector manufacturer, the spray angle and direction is disturbed by the exhaust flow, so CFD results present the Arla32 flow in the exhaust pipe, as can be seen in figure 6, for example.

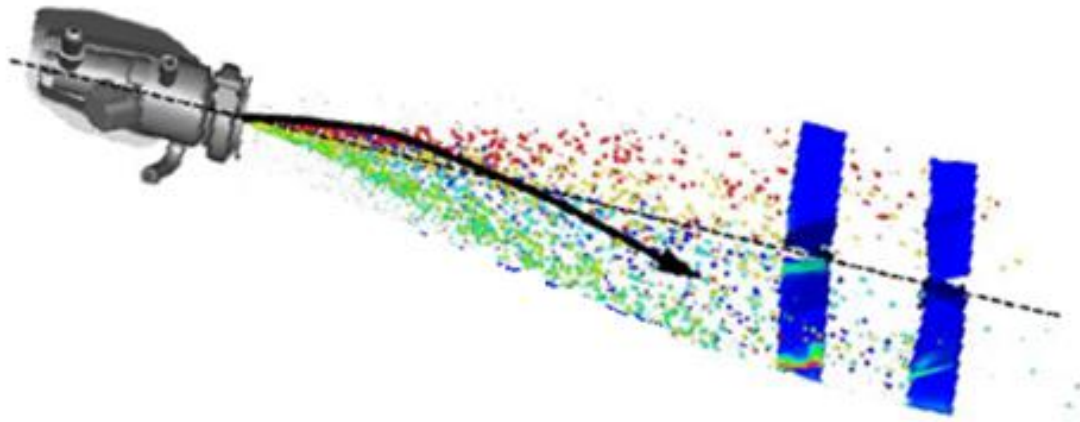

Figure 6. Example of injection flow output from the CFD.

Arla32 flow in the exhaust pipe is the one of the main CFD outputs used to predict deposits. In case of a layout redesign, to understand the spray behavior according to the application parameters becomes a requirement.

Mixers are used to generate turbulent flows. The random motions enable mixing and transport of species quicker than through a molecular diffusion.

\subsubsection{Uniformity Index}

The catalyst reaction occurs inside the substrate channels and depends on the surface contact of the catalyst material and the exhaust gas. For the best conversion efficiency, all the channels must contain the gas flow in ideal conditions, but it is usual the flow being different across the cross section. Due to exhaust pipe routing and mixer turbulence, the flow is not the same at all channels.

The flow uniformity index $\gamma$ is an important indicator, which gives the engineer information about the potential of the substrate. It is proven that the more uniform the flow distribution is, a higher efficiency and a lower pressure loss can be achieved.

The flow uniformity can be calculated from the simulated velocity and its local distribution. A representative value for the efficiency of the substrate is the flow uniformity index $\gamma$, which is calculated in a user function during the simulation, see figure 7 :

$$
\gamma=1-\frac{1}{2 n} \sum_{i=0}^{n} \frac{\left|\phi_{i}-\phi_{\text {mean }}\right| A_{i}}{\phi_{\text {mean }} A_{\text {ges }}} \quad \begin{array}{lll}
n & \ldots \text { number of cells } \\
\phi_{\text {maan }} & \ldots \text { evaluated mean quantity } \\
\phi_{i} & \ldots \text { evaluated local (cell) quantity }
\end{array}
$$

Figure 7 - Uniformity index 
The uniformity index could be understood as the standard deviation from the mean velocity and it always ranges between 0 and 1 . The value $\gamma=1$ means ideal flow conditions (the velocity in the selected cross section is homogeneous). The uniformity index is calculated for substrates right before the monolith's entrance. The figure 8 is an example of result from CFD simulation.

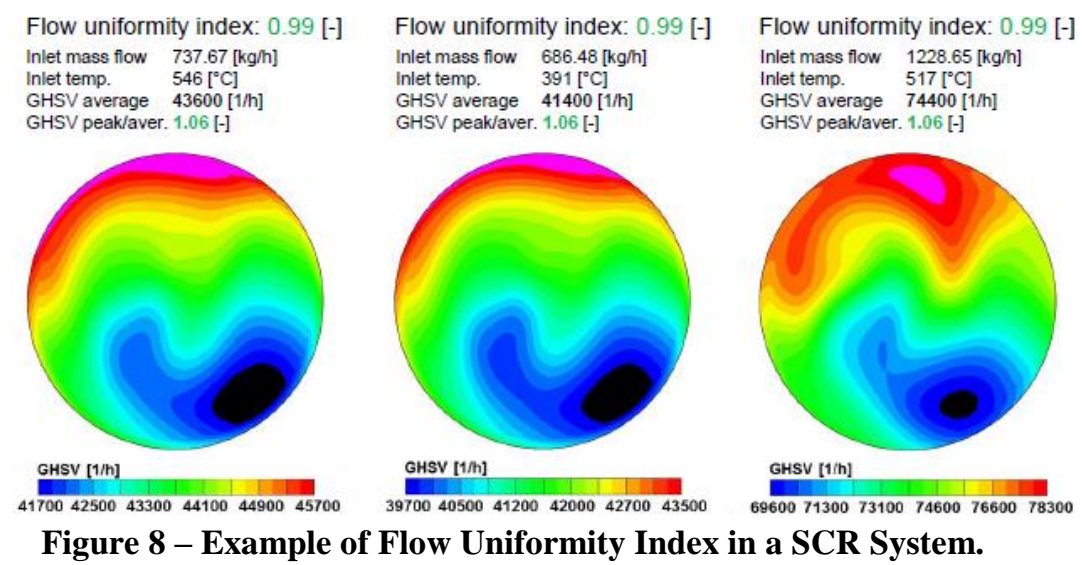

The mixer selection and location will improve the velocity and uniformity on the inlet of the catalyst, thereby increasing the amount of catalyst used. The primary goal of system optimization is to achieve high velocity and species uniformities at the inlet of the SCR. Having high velocity uniformity means that the gas flowing through the SCR catalyst is well distributed. A high species uniformity means that the concentration of the species (ammonia and isocyanic acid) are evenly distributed across the SCR inlet. Without good distribution, the SCR system will be prone to increase DEF consumption, decrease NOx conversion and increase ammonia slip.

\subsubsection{Urea wall film}

In the figure 9 it can be seen some characteristics of the urea drops when it get impacted against the exhaust pipe wall. According to the temperature and weber number, there will be an outcome from an impingement droplet.

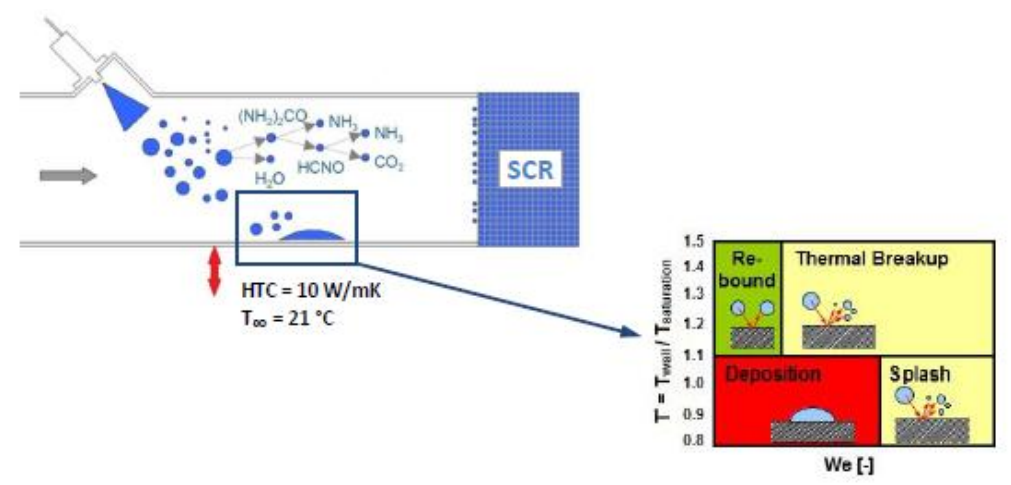

Figure 9 - Characteristic of urea drops in the exhaust pipe.

During an injection event, part of the solution dosed will be evaporated and other part will form a film on the metal surfaces. In the figure 10 it can be seen. After the dosing ceases, the film is also evaporated. If there is enough time and adequate temperature and flow conditions, the complete film is evaporated. 


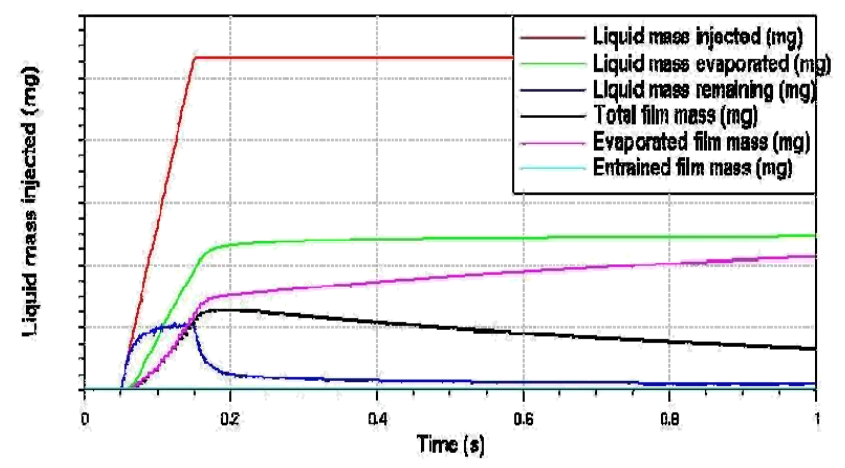

Figure 10 - Characteristic of Arla32 evaporation.

If the conditions are changed or there is more solution dosed, the film could be kept at the pipe.

\subsubsection{Wall Impingement}

AVL Fire[TM] uses Lagrangian particle tracking and Bai-Gosman Wall Impingement for modeling the droplet impingement and the objective is to predict the outcome after the droplet-wall interaction. There are six possible outcomes which are listed below and also shown schematically in figure 11[8].

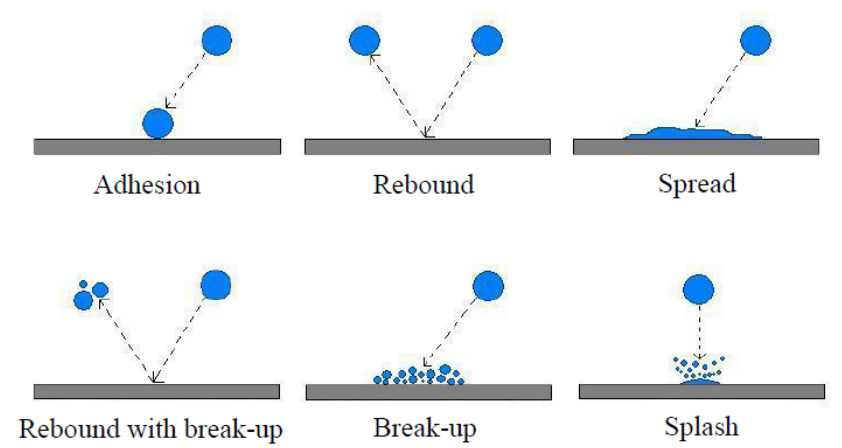

Figure 11 - Schematic figure of the possible outcomes for an impinging droplet.

Depending on the occurring regime, one of these six alternatives will be the result of the impingement. The regime is influenced by four parameters; the Weber number, the Laplace number, the wall temperature and the state of the wall. The wall can be either wet or dry. The wall state was set to wet in this study since the spray droplets have a relatively pronounced course and many droplets will impinge the same area. The first droplet that impinges the wall will interact with a dry wall but when many droplets impinge the same area the wall will be wet. Hence to solve the behavior as accurate as possible the state of the wall was set to wet.

\section{METHODOLOGY}

The aim of this work is to evaluate the probability of urea deposit formation in the SCR system in the region between the injector and the substrate, the uniformity flow in the SCR inlet due to 
the exhaust system layout proposed for the vehicle and characteristics of the mixer and the substrate.

For this study use a diesel engine described in table 2 below. Which it is designed to meet the standard PROCONVE P7 emissions (similar to European Euro V standard). This study uses a SCR system as aftertreatment with vanadium catalyst technology.

Table 2 - Engine characteristics.

\begin{tabular}{|c|c|}
\hline Type & 4 Stroke SI \\
\hline Number of cylinders & 4 in line \\
\hline Aspiration & Turbocharged After-cooled \\
\hline Compression ratio & $16.8: 1$ \\
\hline Firing Order & $1-4-3-2$ \\
\hline Stroke $(\mathrm{mm})$ & 137 \\
\hline Bore $(\mathrm{mm})$ & 105 \\
\hline Cubic displacement (cc) & 4748 \\
\hline Rated horsepower & $165 \mathrm{cv} \mathrm{@} \mathrm{2200} \mathrm{rpm}$ \\
\hline
\end{tabular}

To perform the CFD simulation was used AVL FIRE software together with AVL.

Three operating conditions were defined from ESC emission cycle. In order to provide proper engineering input concerning SCR system layout, three distinct steady state engine out (EO) conditions were defined from engine specifications due to the following criteria, see figure 12 :

- max exhaust gas mass flow rate (C100)

- low exhaust gas temperature (C25)

- low exhaust gas temperature combined with high NOx concentration (A25)

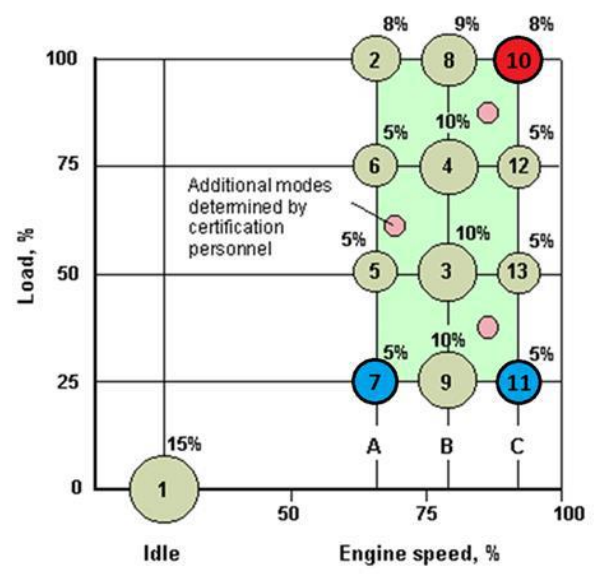

Figure 12 - ESC map with CFD boundary conditions highlighted

After defining the points to be analyzed and the layout of the entire exhaust system from the vehicle as can be seen in figure 13 since turbine outlet until to SCR outlet, this 3D model has been transformed into a mesh and added in the software. The following information is input data to perform the simulation as the constructive characteristics of the substrate, diameter, length, number of substrates, cell density, substrate material, thermal conductivity and coating type are also input data to perform the simulation study. 


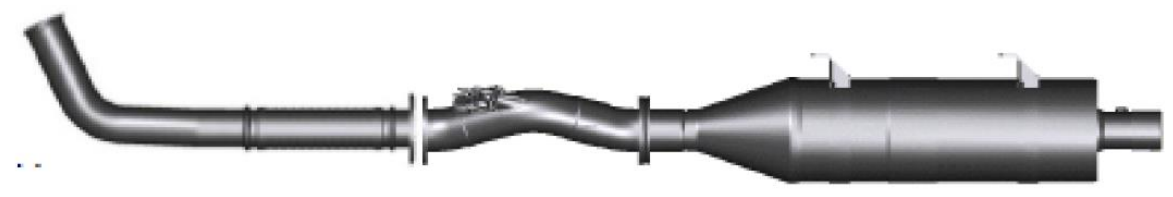

Figure 13 - Exhaust system layout from Vehicle.

The engine data in the 3 points were previously defined measured in a dynamometer, this information is very important for the realization of the simulation, because the closer to reality are the input data, better are the accuracy of the results of this study. The information required for the engine are exhaust flow, exhaust temperature before the urea injector, outlet pressure of the catalyst, ambient temperature, the Arla32 temperature, amount of Arla32 injected and the composition of the exhaust gases that are emitted for the engine, $\mathrm{NOx}, \mathrm{O}_{2}, \mathrm{CO}_{2}, \mathrm{HC}$ and $\mathrm{N}_{2}$. All this information is input into the software for the simulation.

After finish the CFD simulation to verify the possibility of urea deposit formation, will perform a dynamometer test with the same parameters used in the simulation to validate and compare the effectiveness of the simulation results. The test on the dynamometer was performed in two steps: the first step an evaluation of 5 hours in each three points evaluated in the CFD, the second step perform a dynamometer durability with 500 hours to simulate the vehicle cycle usage in the field (urban bus route), to prove that the design does not present risk of urea deposits in the exhaust system. The figure 14 below shows the engine and exhaust system from vehicle assembled in a transient dynamometer in MWM Tech Center for testing.

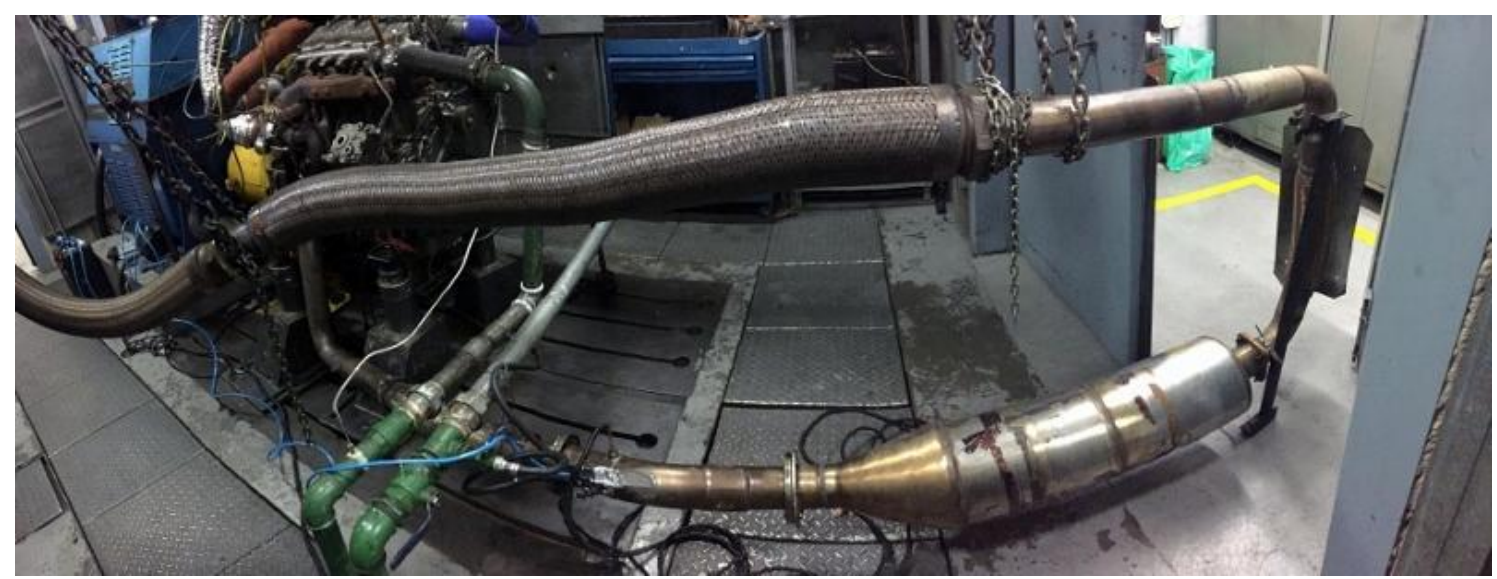

Figure 14 - Engine and exhaust system from vehicle assembled in dynamometer.

In graphs 2 and 3 are shown the engine conditions (engine speed and torque) to perform the durability in a transient cycle to check if the exhaust system layout from vehicle has a risk to cause urea deposits formation. The durability cycle dynamometer was based on a vehicle operation cycle, urban bus. 


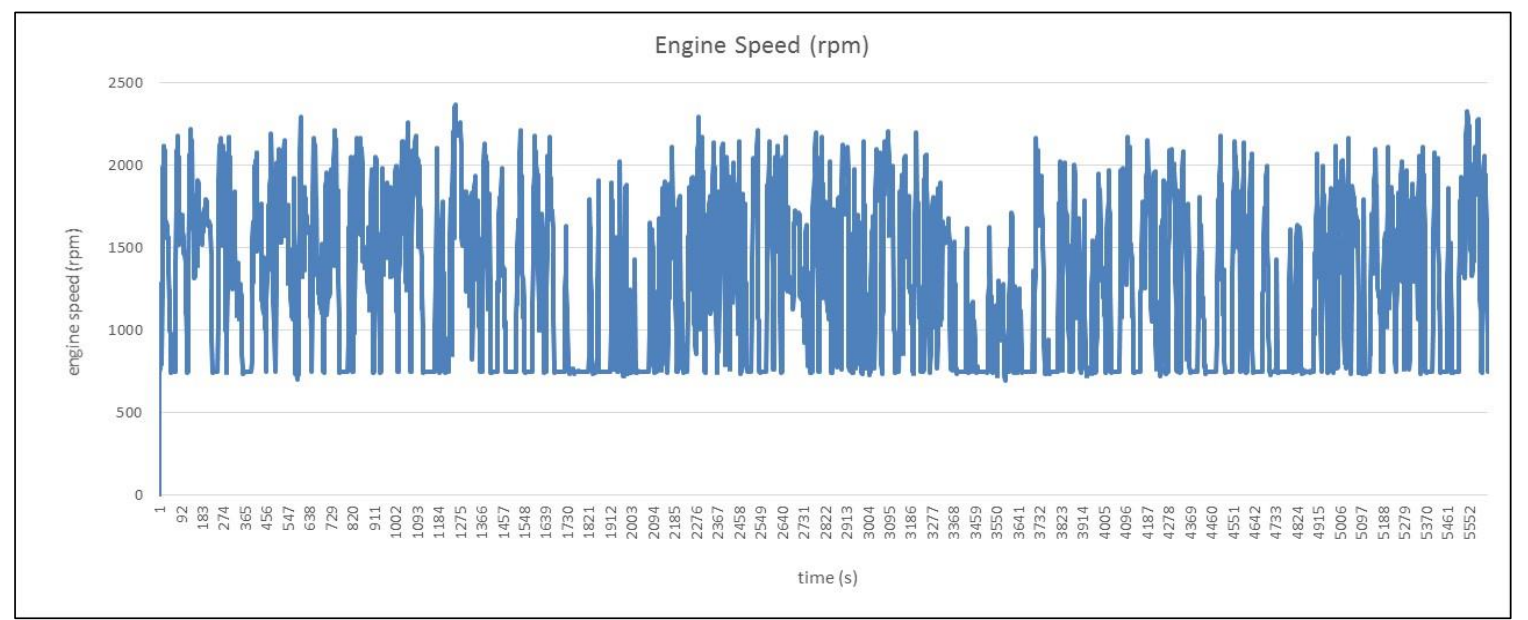

Graph 2 - Engine speed versus time.

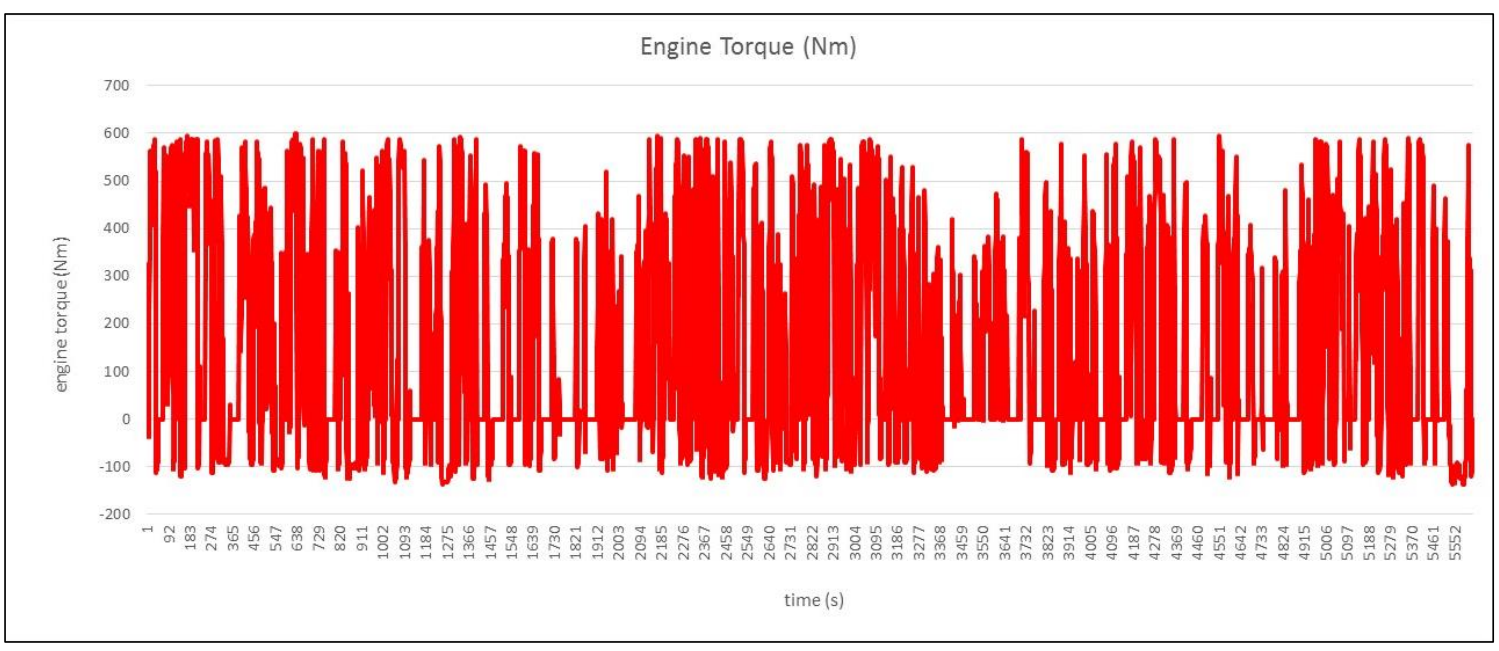

Graph 3 - Engine torque versus time.

\section{RESULTS}

In this chapter will present the results obtained in the CFD simulation and validation tests on dynamometer.

In this study, selected engine operating points conditions were chosen in other to cover different characteristics of exhaust gas, the points selected are Mode A25, C25 and C100 from ESC emission test.

\subsection{Wall film impingement}

Wall film impingement on pipe walls is performed on shown partition. Wall film assessment on mixer and blade is done individually. Results of wall film deposition are shown per injection and accumulated after 12 injections. The figure 15 below shows the components where may occur urea deposits. 


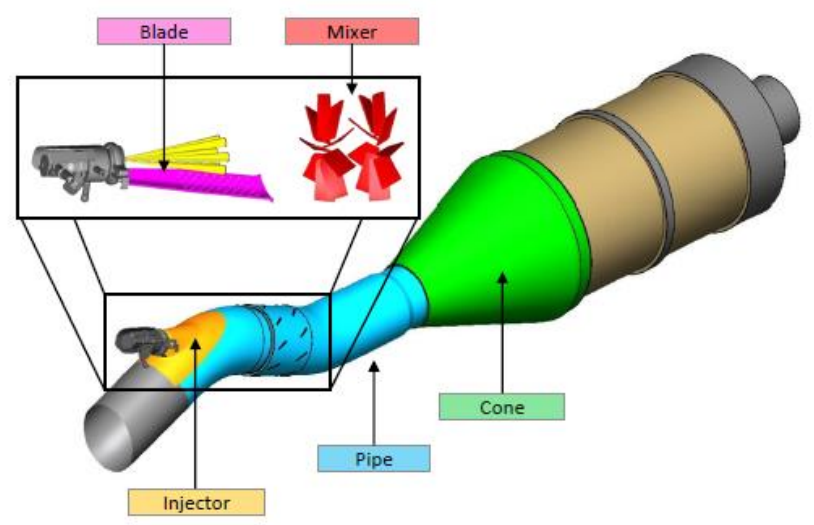

Figure 15 - SCR system componentes.

Results below show the accumulated state of the system after 3s (12 injections). At A25 exhaust gas temperatures and clean spray targeting enhance the droplet evaporation within the gas flow. Low surface temperatures $\left(270^{\circ} \mathrm{C}\right)$ increase wall film build-up at the mixer and the pipe.

The graph below show the film impingement per dosing event in a Mode A25.

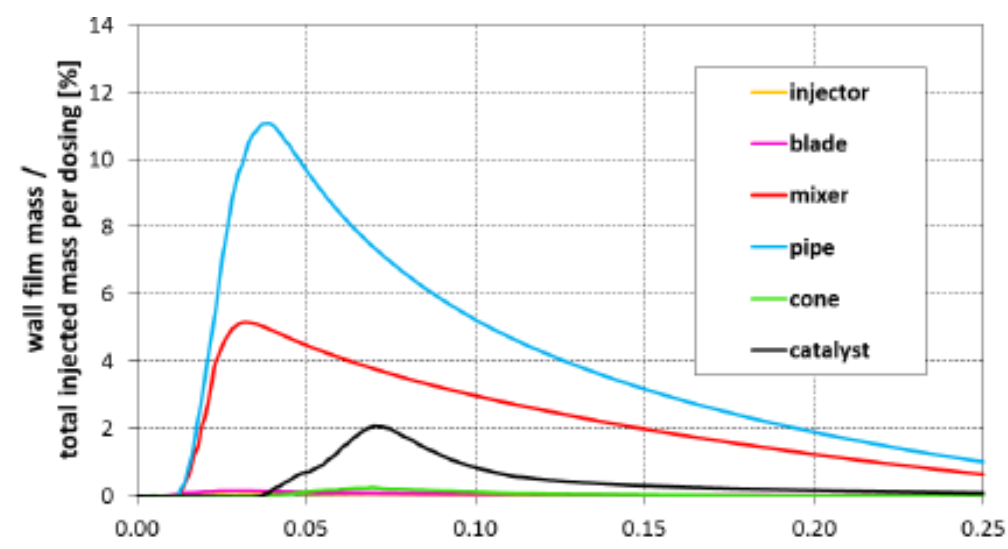

Graph 4 - Urea film impingement per dosing - Mode A25.

The figure 16 below shows the event of urea injection in Mode A25. The low exhaust temperatures avoid quick spray evaporation which leads to droplets impinging on the decomp pipe and mixer. According to the simulation in the mixer area there is a small possibility of occurring urea deposit.

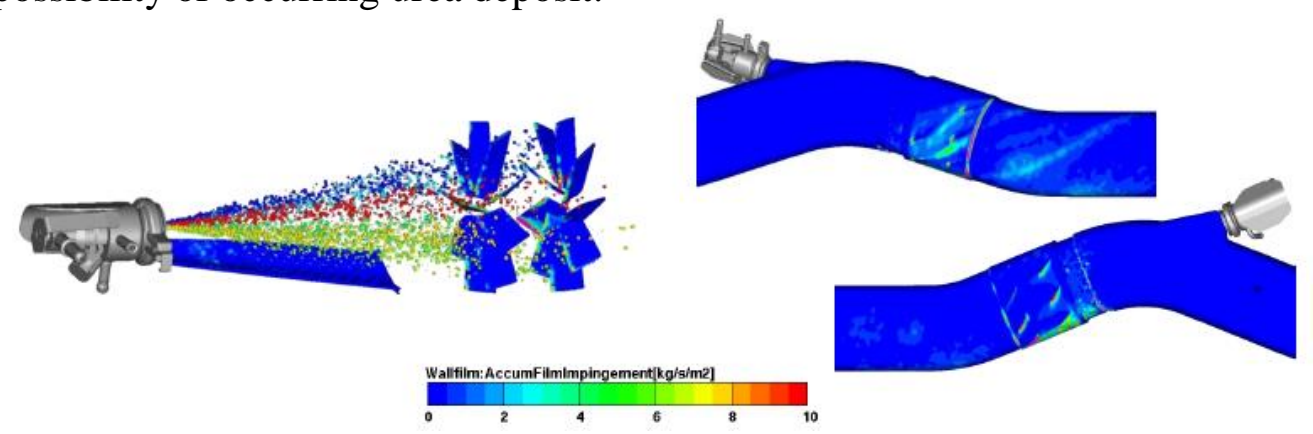

Figure 16 - Event of Arla32 injection - Mode A25. 
The graph 5 below shows the film impingement per dosing event in a Mode C25.

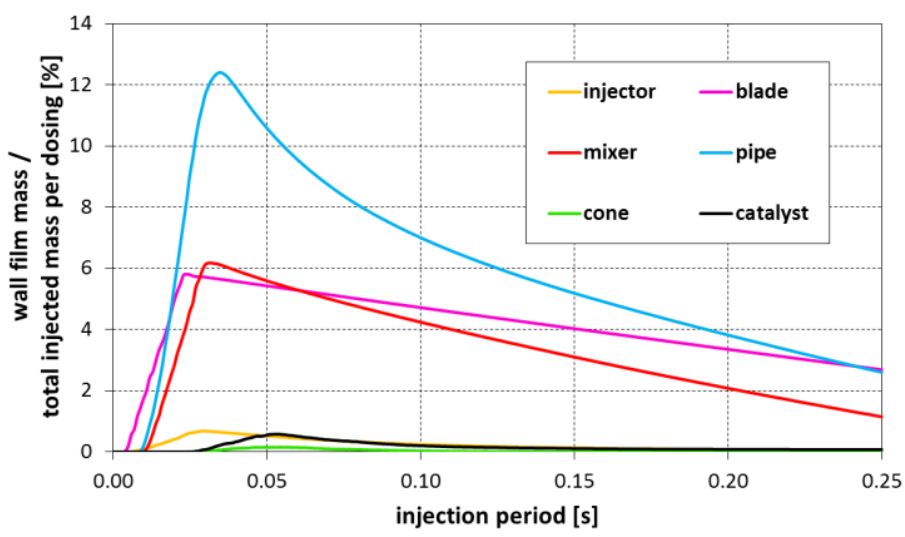

Graph 5 - Urea film impingement per dosing - Mode C25.

The figure 17 below shows the event of urea injection in Mode C25. The intense exhaust mass flow rate increase spray deflection of small droplets at the injector area, which increases wall film here and reduces spray impingement on the catalyst. According to the simulation in the mixer area and the blade there is a small possibility of occurring urea deposit.

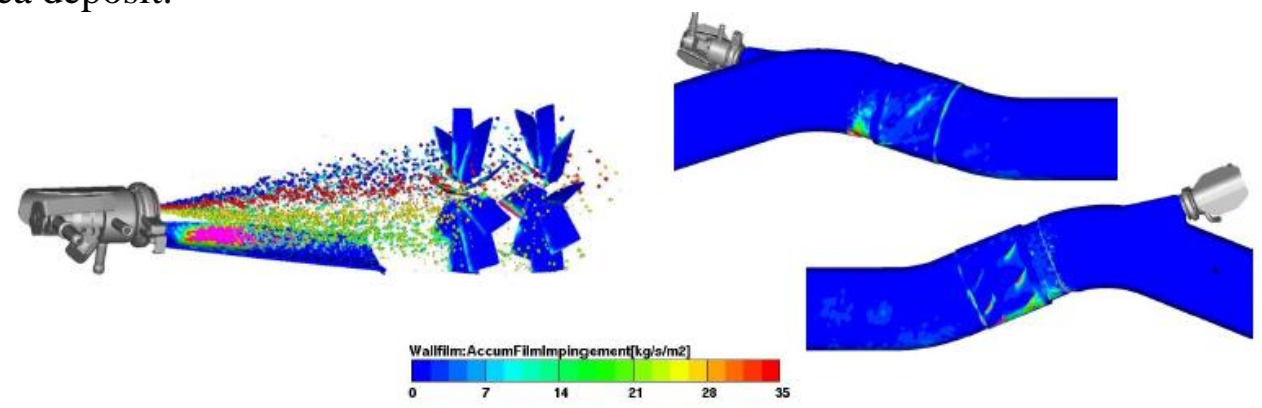

Figure 17 - Event of Arla32 injection - Mode C25

The graph 6 below shows the film impingement per dosing event in a Mode C100.

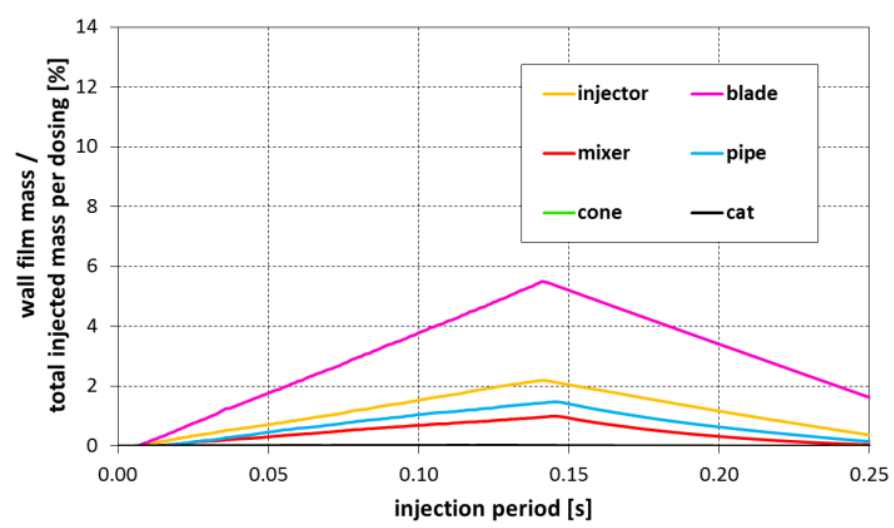

Graph 6 - Urea film impingement per dosing - Mode C100.

The figure 18 below shows the event of urea injection in Mode C100. The large mass flow rate deflects small droplets from the spray target and increases the wall film at the injector location. Wall film at injector could become an issue. the large mass flow rate deflects small droplets from the spray target and increases the wall film at the injector location. 


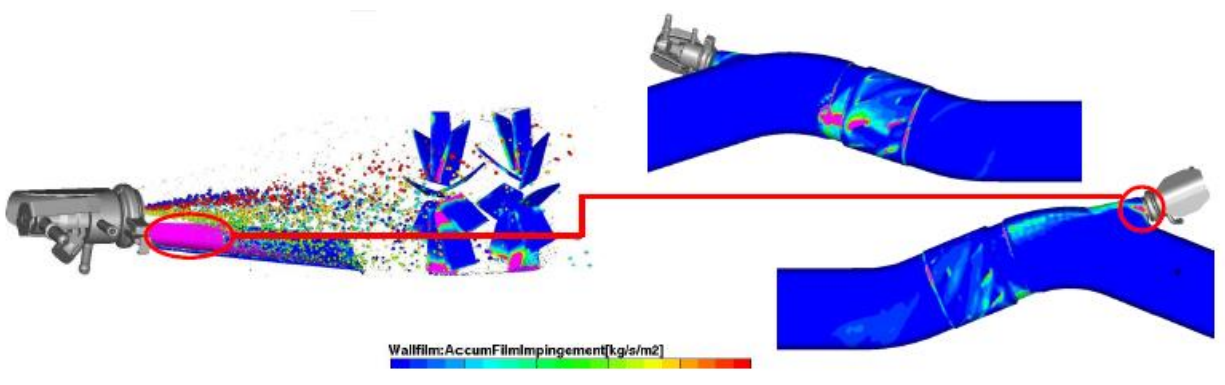

Figure 18 - Event of Arla32 injection - Mode C100.

At Mode C100 the wall film accumulation at the injector is the highest, see figure 19 below. The combination of decreasing wall temperature and accumulating wall film at injector could become a urea deposit in this region.

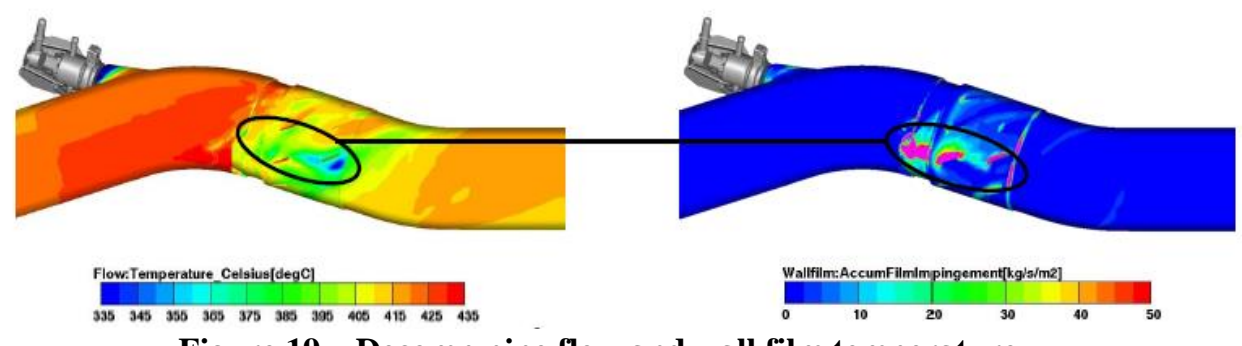

Figure 19 - Decomp pipe flow and wall film temperature.

After conclude the simulation was performed a 5hours test in the same condition of simulated points to verify the correlation between simulation and the real conditions. The engine installed in dynamometer and also the entire exhaust system of the vehicle and Arla32 dosing system.

After run 5 hours in a Mode A25 mixer shows small traces of deposits. In a Mode C25 the SCR system not present any traces of deposits. In a Mode C100 present a traces of urea deposits in a mixer according figure 20 below.

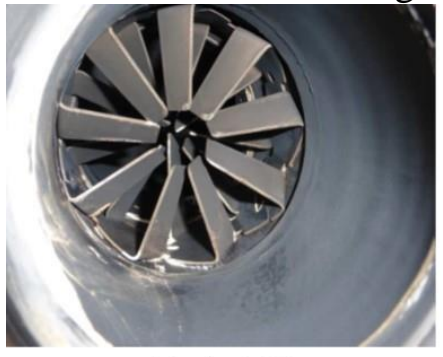

Mode A25

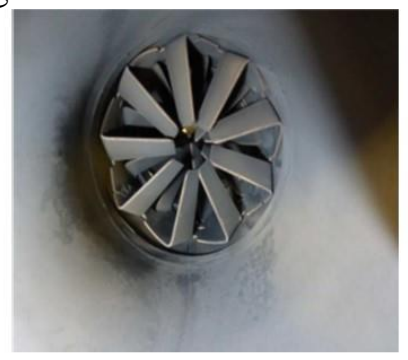

Mode C25

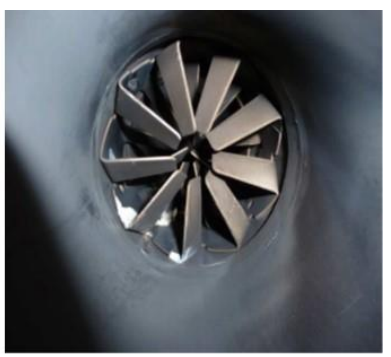

Mode C100

Figure 20 - Mixer after run 5 hours.

After the dynamometer tests showed a correlation between the results obtained in the simulation and results seen in the engine test. The results showing the possibility of urea deposits in a mixer because the wall temperature lower than the exhaust gas temperature and due to a not complete urea evaporation.

After performed the correlation tests between simulation and dynamometer, where showed correlation, was defined and set up a durability test to simulating the vehicle operating conditions, was used the operating cycle of an urban bus due to transient operation, due to 
the exhaust temperatures in the route not so high, which can promote the deposits formation in a SCR system. Thus, the route was measured and transforming this route in a dynamometer durability test cycle with 500 hours of duration. Used a transient dynamometer for this testing.

The durability cycles can see in the graphs 2 and 3. To each 100 hours of durability, the test was stopped to disassemble the SCR system to verify the mixer if will show urea deposits. The figure 21 below shows the result of the check the exhaust system every 100 hours of testing, from the beginning to the completion of the dynamometer durability.

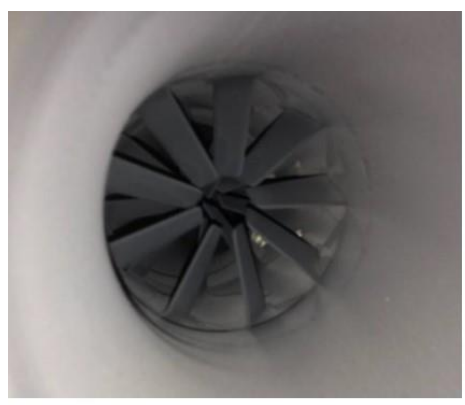

0 hour

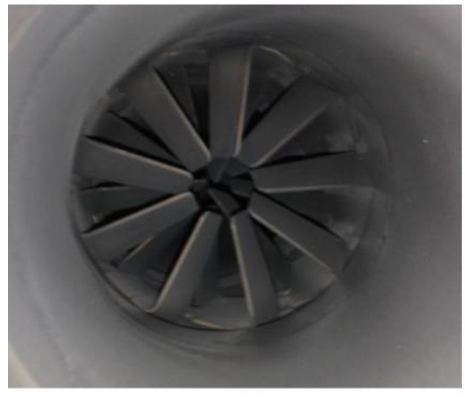

300 hours

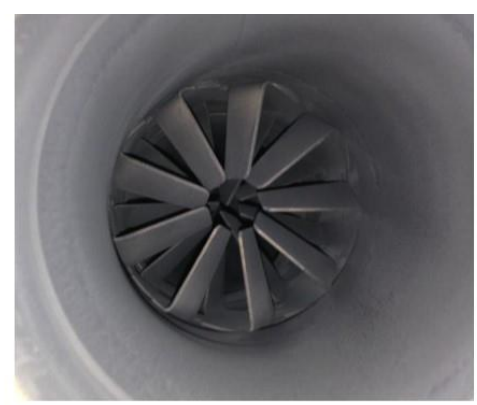

100 hours

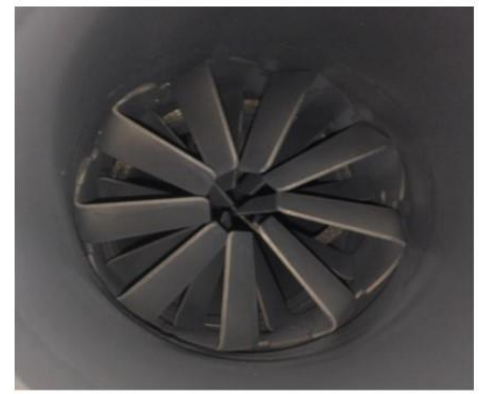

400 hours

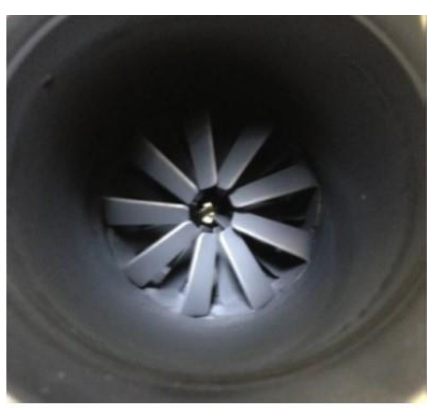

200 hours

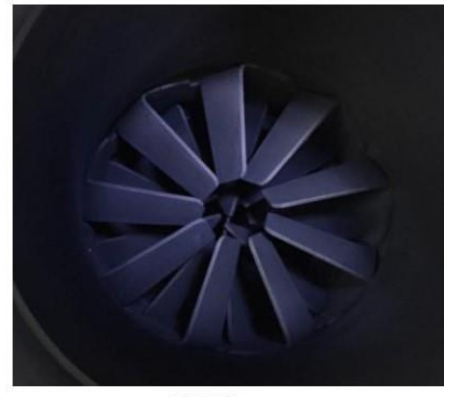

500 hours

Figure 21 - Mixer during durability test.

As can be seen in figure $\mathrm{xx}$ above, in an urban bus cycle where the temperature of the exhaust gas is low because the operating conditions (transient cycle), there was no deposits formation in the SCR system as had been identified the possibility of traces of urea in CFD simulation.

\section{CONCLUSIONS}

One option to reduce emission is SCR system, this technology is the preferred solution for meeting the new emissions levels due to stringent legislation limits for Heavy Duty applications.

The aim of this study was to conduct a study in order to verify an SCR system design cannot present urea deposit formation, as if there a deposit formation in the SCR system, failures can happen as the decrease NOx conversion due to decrease the inlet surface area in the catalyst and also increase the engine exhaust backpressure. 
The CFD simulation and the tests performed in dynamometer present a good correlation, being possible to use the same evaluation method for different types of exhaust system layout, allowing you to choose the best layout for vehicle installation, with an option to perform the simulation and only validated in dynamometer with the system to present the best answer.

The tests performed in dynamometer to validate the layout option is important because there are events that occur only in the engine and are not predictable to meet in the simulation, especially in transient conditions. Therefore, perform the engine test validation with the SCR system is important so that there is the possibility of deposits when the vehicle is in the field.

As can be seen in this work the simulation only indicates that there may be a possible to occur a urea deposition, but in the case of this study was not possible in the simulation verify what would be the amount of deposit formed. In the test dynamometer is possible to checking the amount deposited and to be quantified. 


\section{REFERÊNCIAS}

[1] MAJEWSKI, W.A. What are diesel emissions. 2012. DieselNet Technology Guide]. Available from: http://dieselnet.com/tech/emi_intro.php\#intro. Access: 29/05/2016.

[2] Diesel Catalysts. 2004. DieselNet Technology Guide. Available from: http://dieselnet.com/tech/cat_diesel.php. Access: 29/05/2016.

[3] BIRKHOLD, F., et al., Analysis of the Injection of Urea-Water-Solution for Automotive SCR DeNOx-Systems: Modeling of Two-Phase Flow and Spray/Wall-Interaction, 2006, SAE International.

[4] ZHANG, X., M. Romzek, and C. Morgan, 3-D Numerical Study of Mixing Characteristics of NH3 in Front of SCR, 2006, SAE International.

[5] XU, L., et al., Laboratory and Engine Study of Urea-Related Deposits in Diesel Urea-SCR AfterTreatment Systems, 2007, SAE International.

[6] UDO, F., Spray Systems, in Multiphase Flow Handbook2005, CRC Press. p. 8-1-8-100.

[7] CHEN, C., et al., Detailed Modeling of Liquid Fuel Sprays in One-Dimensional Gas Flow Simulation, 2004, SAE International.

[8] SAMUELSSON, Emelie; HOLMBERG, Sara. Breakup and Mixing in a Pipe Upstream of a SCR Catalyst. Sweden: CHALMERS UNIVERSITY OF TECHNOLOGY, 2013. 